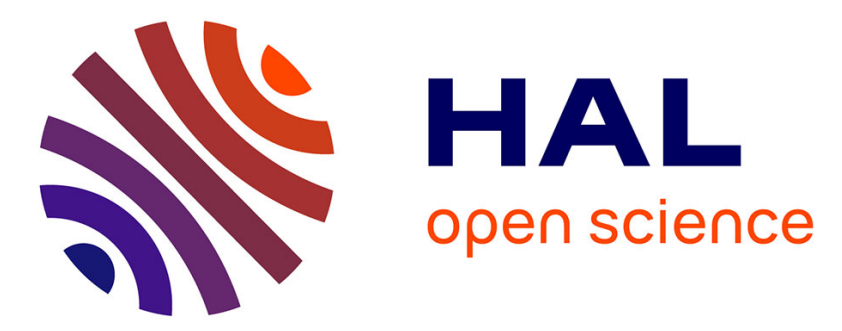

\title{
Polymerization Initiated by Organic Electron Donors
}

Julie Broggi, Marion Rollet, Jean-Louis Clément, Gabriel Canard, Thierry

Terme, Didier Gigmes, Patrice Vanelle

\section{To cite this version:}

Julie Broggi, Marion Rollet, Jean-Louis Clément, Gabriel Canard, Thierry Terme, et al.. Polymerization Initiated by Organic Electron Donors. Angewandte Chemie International Edition, 2016, 55 (20), pp.5994-5999. 10.1002/anie.201600327 . hal-01427954

\section{HAL Id: hal-01427954 \\ https://hal.science/hal-01427954}

Submitted on 6 Jan 2017

HAL is a multi-disciplinary open access archive for the deposit and dissemination of scientific research documents, whether they are published or not. The documents may come from teaching and research institutions in France or abroad, or from public or private research centers.
L'archive ouverte pluridisciplinaire HAL, est destinée au dépôt et à la diffusion de documents scientifiques de niveau recherche, publiés ou non, émanant des établissements d'enseignement et de recherche français ou étrangers, des laboratoires publics ou privés.

\section{(1) (1) $\$$}

Distributed under a Creative Commons Attribution - NonCommercial - NoDerivatives| 4.0 


\title{
Polymerization Initiated by Organic Electron Donors
}

\author{
Julie Broggi, ${ }^{* a,+]}$ Marion Rollet, ${ }^{[a, t]}$ Jean-Louis Clément, ${ }^{[a, t]}$ Gabriel Canard, ${ }^{[b]}$ Thierry Terme, ${ }^{[a, t]}$ Didier
} Gigmes, ${ }^{[a, \pm]}$ and Patrice Vanelle ${ }^{*[a,+]}$

\begin{abstract}
Polymerization reactions using organic electron donors (OED) as initiators are presented herein. The metal-free polymerization of various activated alkene and cyclic ester monomers was performed in short times, under mild conditions, using small amounts of organic reducing agents and without the need for co-initiators or activation by photochemical, electrochemical or other methods. Hence, OED-initiators allow the development of an efficient, rapid and room temperature process, responding to energy-friendly, cost-efficient and secure technical specifications. Mechanistic investigations support an electron-transfer initiation pathway leading to the reduction of the monomer.
\end{abstract}

Reducing agents with totally neutral organic structures and exceptionally negative redox potentials have gained astonishing advances and a renewed interest (Figure 1). ${ }^{[1]}$ Strong organic electron donors (OEDs) are capable of single- or doubleelectron transfers to organic substrates under mild conditions, promoting bond formations through the generation of radical or anionic intermediates. Among others, Murphy and coworkers made major contributions by demonstrating the efficiency of OEDs in the reduction of challenging substrates, such as aryl halides or arenes, usually achieved by means of metallic reducers (Scheme 1).[1,2]

In order to further study the potential of OEDs, we decided to tackle the reduction of hitherto uninvestigated functional groups and explore unprecedented applications. Notably, we focused on the initiation of chain-growth polymerizations by electrontransfer. Typical redox initiating systems combine a reducing agent (metal) and a radical priming source. ${ }^{[3,4]}$ Examples where the monomer itself acts as one component of the redox pair are rare and generally use constraining alkali-metal systems. ${ }^{[5,6]}$ In 1977, Tsuda and co-workers reported a case of free-radical polymerization via formation of an electron-transfer complex between an amine and a vinyl monomer. ${ }^{[7]}$ Considering that aminoethylene derivatives are more powerful reducers than amines, ${ }^{\left[{ }^{a]}\right.}$ we assumed that they could be remarkable initiators. We report herein an original concept of chain-growth polymerization induced by spontaneous and intrinsic electron transfer between organic reducers and various monomers. As our OED-system could lead to radical or anionic priming species, mechanistic investigations were also undertaken to better understand the initiation and chain propagation pathways.

[a] Dr J. Broggi, Dr M. Rollet, Dr J-L. Clément, Prof T. Terme, Dr D. Gigmes, Prof P. Vanelle

Aix Marseille Université, CNRS, ICR UMR 7273

† LPCR (ICR)

$\ddagger$ CROPS (ICR)

13397, Marseille, France

E-mail: julie.broggi@univ-amu.fr patrice.vanelle@univ-amu.fr

[b] Dr G. Canard

Aix Marseille Université, CNRS, CINaM UMR 7325

13288, Marseille, France

Supporting information for this article is given via a link at the end of the document.

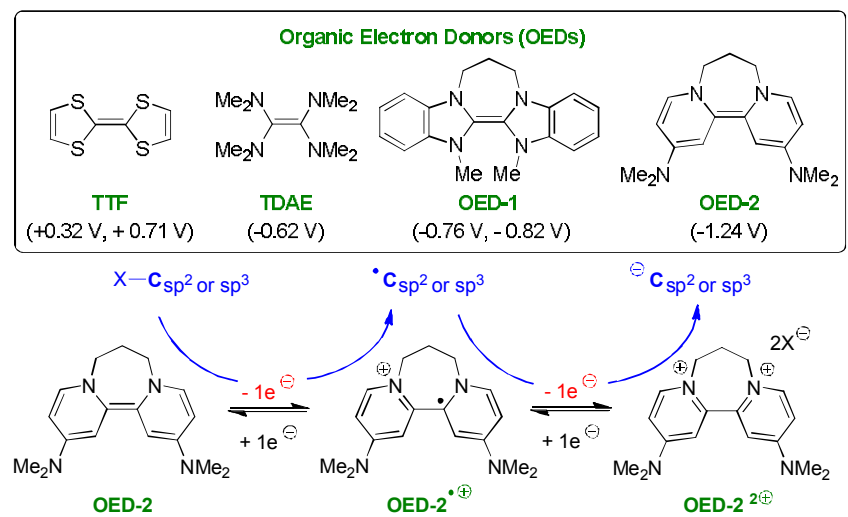

Figure 1. Selected OEDs with their redox potentials ( $E_{1 / 2}$ (vs $\left.S C E\right)$ ) and Redox equilibria of OED-2.

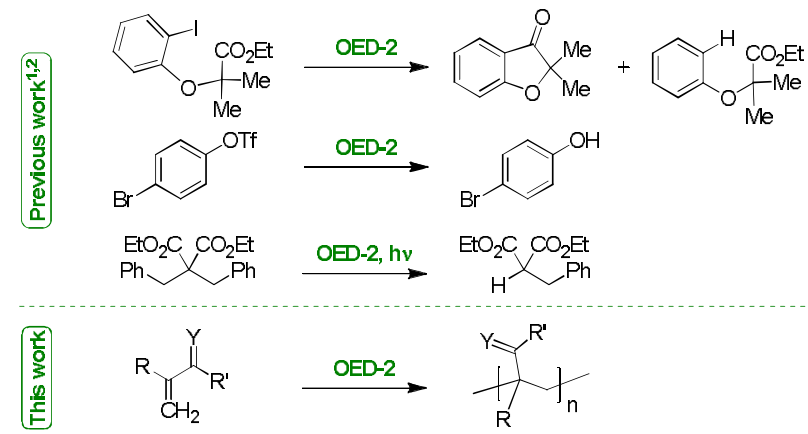

Scheme 1. Reduction of organic substrates by OED-2

The polymerization process was first studied using ethyl methacrylate (EMA) as monomer and various organic electron donors as initiators (Table 1). In the presence of the bispyridinylidene OED-2 (10 mol\%), ${ }^{[8]}$ EMA was totally converted into the expected poly(ethyl methacrylate) (PEtMA) in less than 3 min (Entry 5). The weight-average molar mass $\left(M_{w}\right)$ and the number-average molar mass $\left(M_{n}\right)$ were of 13100 and 9900 g.mol ${ }^{-1}$, respectively, indicating a dispersity $(Đ)$ of 1.33 . The spontaneous and immediate initiation of the polymerization reaction was slightly exothermic $\left(35^{\circ} \mathrm{C}\right)$ and accompanied by a change of color (from dark purple to blood red), attributed to the formation of a stabilizing complex between the anionic propagating species and the oxidized form OED-22+. The experimental difficulties (side reactions, early chain termination) often encountered with ionic polymerizations of alkyl methacrylates were not experienced here.[3] Our simple methodology did not require particular precautions such as special vessels and conditions, secure handling or meticulous monomer and solvent purifications. Neither solvent or additive, nor light- or thermal-activation was necessary.

On the other hand, tetrakis(dimethylamino)ethylene TDAE and tetrathiafulvalene TTF were not able to initiate the polymerization reaction (Entries 1-2). Compared to OED-2 [ $E_{1 / 2}$ 
$=-1.24 \mathrm{~V}]$, the lower reduction potentials of these electron donors could explain their lack of reactivity $\left[E_{1 / 2}=-0.62 \mathrm{~V}\right.$ and $E_{1 / 2}=+0.32,+0.71 \mathrm{~V}$, respectively (Figure 1 )]. This hypothesis was consistent with the results observed using benzimidazolebased donor OED-1 which exhibits an intermediate redox potential $\left[E_{1 / 2}=-0.76,-0.82 \mathrm{~V}\right] .^{[9]}$ At $25^{\circ} \mathrm{C}$, no reaction was observed, while at $120^{\circ} \mathrm{C}$, the electron-transfer occurred but oligomers were recovered (Entries 3-4). Formation of radical species and chain transfer reactions could explain the low molecular weights observed with OED-1. Unlike OED-2 able to initiate double-electron transfers at r.t. to generate carbanions, OED-1 is known as a single-electron transfer reagent allowing the formation of radicals under thermal activation. [9,10]

Table 1. Polymerization of EMA initiated by OEDs. ${ }^{[a]}$

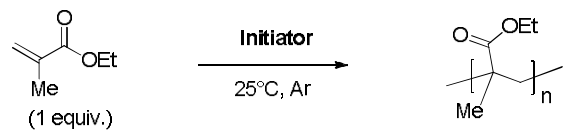

\begin{tabular}{|c|c|c|c|c|c|c|c|c|}
\hline Entry & \multicolumn{2}{|c|}{$\begin{array}{l}\text { Initiator } \\
(\mathrm{mol} \%)\end{array}$} & Solvent & Time & $\operatorname{Conv}(\%)^{[b]}$ & $M_{\mathrm{n}}$ & $M_{\mathrm{w}}$ & $\bigoplus$ \\
\hline 1 & TDAE & (10) & neat & $24 \mathrm{~h}$ & 0 & - & - & - \\
\hline 2 & TTF & (10) & neat & $24 \mathrm{~h}$ & 0 & - & - & - \\
\hline 3 & \multicolumn{2}{|c|}{ OED-1 (10) } & DMF & $24 \mathrm{~h}$ & 0 & - & - & - \\
\hline 4 & \multicolumn{2}{|c|}{ OED-1 (10) } & $\mathrm{DMF}, 120^{\circ} \mathrm{C}$ & $2 \mathrm{~h}$ & 99 & \multicolumn{3}{|c|}{ oligomers } \\
\hline 5 & \multicolumn{2}{|c|}{ OED-2 (10) } & neat & $<3 \mathrm{~min}$ & 95 & 9900 & 13100 & 1.33 \\
\hline 6 & & (5) & neat & $10 \mathrm{~min}$ & 92 & 12000 & 20200 & 1.67 \\
\hline 7 & & (2) & neat & $4 \mathrm{~h}$ & 95 & 28000 & 161000 & $5.76^{[c]}$ \\
\hline 8 & & (1) & neat & $24 \mathrm{~h}$ & 25 & $\varepsilon$ & $\varepsilon$ & $\varepsilon$ \\
\hline 9 & & (5) & neat, $0^{\circ} \mathrm{C}$ & $3 \mathrm{~h}$ & 95 & 17300 & 44800 & 2.55 \\
\hline 10 & & (5) & neat, $-30^{\circ} \mathrm{C}$ & $24 \mathrm{~h}$ & $<5$ & - & - & - \\
\hline 11 & \multicolumn{2}{|c|}{ OED-2 (5) } & DMF & $30 \mathrm{~min}$ & 96 & 18500 & 31000 & 1.68 \\
\hline 12 & & & $\mathrm{CH}_{3} \mathrm{CN}$ & $24 \mathrm{~h}$ & 30 & \multicolumn{3}{|c|}{$180<M<1800$} \\
\hline 13 & & & THF & $24 \mathrm{~h}$ & $0^{[d]}$ & - & - & - \\
\hline 14 & & & $\mathrm{C}_{6} \mathrm{D}_{6}$ & $24 \mathrm{~h}$ & $0^{[d]}$ & - & - & - \\
\hline
\end{tabular}

[a] EMA (1 equiv.), initiator (1-10 mol\%), neat or solvent $(1 \mathrm{M}), 25^{\circ} \mathrm{C}, \mathrm{Ar} . \mathrm{Mn}$ and $M_{\mathrm{w}}$ determined by SEC analysis (Eluent THF). [b] ${ }^{1} \mathrm{H}$ NMR conversion. [c] multipopulated. [d] Full conversion reached upon solvent evaporation.

The performance of OED-2 was then compared at different loadings and in different solvents (Table 1). Significantly, we found that the well-defined and solid form of OED-2 allowed an accurate control of the quantity of initiator introduced, enabling to tune the length of the polymer chains. The number-average molar mass $\left(M_{n}\right)$ increased (up to $28000 \mathrm{~g} \mathrm{~mol}^{-1}$ ) as the number of equivalents of initiators decreased (Entries 5-7), following a conventional controlled polymerization behavior. The initiator loading could be decreased to $2 \mathrm{~mol} \%$ without change in the rate of conversion (95\%) though the reaction time increased to $4 \mathrm{~h}$ and led to a multipopulated distribution (Entry 7 ). While the reaction was sluggish at $-30^{\circ} \mathrm{C}$ (Entry 10), polymerization proceeded at $0^{\circ} \mathrm{C}$ with a good conversion of $95 \%$ in $3 \mathrm{~h}$ and increased $M_{n}$ (Entry 9). Kinetic study of the polymerization revealed a process without inhibition period and a linear increase in number-average molar mass $\left(M_{n}\right)$ rate versus conversion (Figure 2). The observation of the rapid priming and the linear growth of the polymer chain through the course of the reaction indicated a pseudo-controlled process, even if the dispersities are quite large.

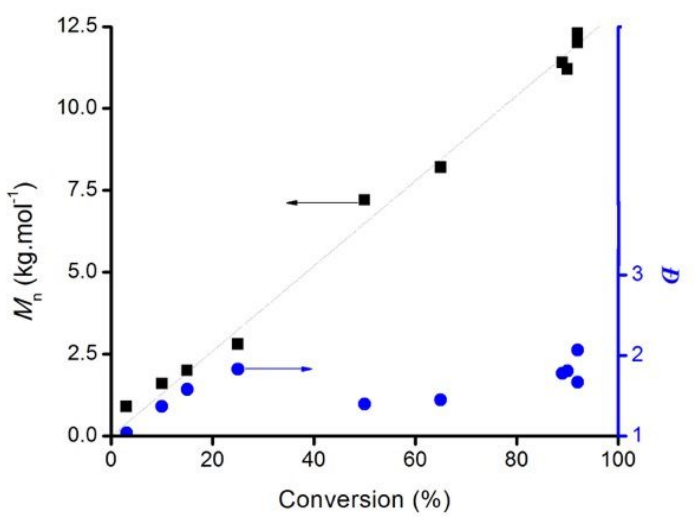

Figure 2. Kinetic of the polymerization of EMA using OED-2 (5 mol\%), sequence of $1 \mathrm{~min}$ intervals over $10 \mathrm{~min}$.

The rate of the chain-growth polymerization was also strongly influenced by the solvent. The reaction only took place in highly polar aprotic solvents and the conversion rate increased with the polarity of the solvent. In DMF (1M), the molecular weights were higher than the results obtained without solvent, for similar conversion rate (96\%) and reaction time (30 min) (Entry 11). On the other hand, the polymerization was very slow in acetonitrile, forming only oligomers, and null in tetrahydrofuran or benzene$d^{6}$ (Entries 12-14). Surprisingly, complete removal of the solvent, by evaporation after $24 \mathrm{~h}$, led to full conversion into the expected polymer in few minutes. Solvents can dramatically affect polymerization rates due to preferential solvation interactions with either the initiator or the propagating species. [3] Equivalent reduction potential values $(\approx-1.25 \mathrm{~V})$ were obtained for OED-2 in DMF, THF or $\mathrm{CH}_{3} \mathrm{CN}$ and suggest that EMA should be reduced equally in these solvents. ${ }^{[1]}$ Hence, the lack of reactivity in THF is unlikely to be a problem of electron-transfer initiation but rather of propagation. In ionic polymerization, increased solvent polarity favors the formation of solvent-separated ion pairs, more reactive than the tight ion pairs that predominate in solvents of low polarity. ${ }^{[3]}$ We thus attributed it to a solvent cage effect on the complex formed between the anionic intermediate and OED$2^{2+}$, preventing the chain propagation. This particularity offers an interesting concept of latent chain-propagation system that could be activated upon evaporation of the solvent.

To further support the versatility of our system, polymerization of a range of monomers was examined using $5 \mathrm{~mol} \%$ of initiator (Table 2). Acrylates and acrylonitrile polymerized smoothly and full ${ }^{1} \mathrm{H}$ NMR conversions were reached in few minutes. As well, 
the cyclic $\alpha, \beta$-unsaturated cyclohexenone was converted into the corresponding polymer in less than 1 minute with high $M_{w}$ and $M n$. The high dispersity $(\boxminus=3.59)$ of the fast polymerizing poly(butyl acrylate) could be decreased to 1.5 under more diluted conditions. As the poly(acrylamide) precipitated upon its formation in DMF, the reaction was run for $24 \mathrm{~h}$ and the conversion (97\%) determined after drying the crude. Ringopening polymerization of the D,L-lactide was also achieved although it required a longer reaction time to reach total conversion and led to a relatively low $M_{n}$.

Table 2. Scope of the polymerization initiated by OED-2.[a]

\begin{tabular}{|c|c|c|c|c|c|c|c|}
\hline \multirow[b]{2}{*}{ Monomer } & \multirow{2}{*}{$\begin{array}{l}\text { Monomer } \\
\text { (1 equiv.) } \\
\text { Solvent }\end{array}$} & \multirow[b]{2}{*}{ Time } & \multirow{2}{*}{$\begin{array}{c}\text { ED-2 (5 mol\%) } \\
25^{\circ} \mathrm{C}, \mathrm{Ar} \\
\text { Polymer }\end{array}$} & \multirow{2}{*}{$\begin{array}{l}\rightarrow \\
\operatorname{Conv}(\%)^{[b]}\end{array}$} & olymer & \multirow[b]{2}{*}{$M_{\mathrm{w}}$} & \multirow[b]{2}{*}{$\bigoplus$} \\
\hline & & & & & $M_{\mathrm{n}}$ & & \\
\hline Ethyl methacrylate & neat & $10 \mathrm{~min}$ & & 92 & 12000 & 20200 & 1.67 \\
\hline $\begin{array}{l}\text { Me } \\
\text { Methyl methacrylate }\end{array}$ & neat & $1 \mathrm{~min}$ & & 95 & 13200 & 17200 & 1.30 \\
\hline$\overbrace{\text { Butyl Acrylate }}^{\mathrm{O}}$ & $\begin{array}{c}\text { neat } \\
\text { DMF (1M) }\end{array}$ & $\begin{array}{l}<1 \min \\
2 h^{[c]}\end{array}$ & & $\begin{array}{l}>99 \\
>99\end{array}$ & $\begin{array}{l}1700 \\
5600\end{array}$ & $\begin{array}{l}6000 \\
8600\end{array}$ & $\begin{array}{l}3.59 \\
1.52\end{array}$ \\
\hline Acrylonitrile & neat & $<1 \min$ & & $>99$ & 5000 & 9200 & $1.84[\mathrm{~d}]$ \\
\hline Cyclohexenone & neat & $<1 \min$ & & $>99$ & 15800 & 22900 & $1.45^{[\mathrm{d}]}$ \\
\hline Acrylamide & DMF (1M) & $24 \mathrm{~h}^{[\mathrm{c}]}$ & & 97 & 1400 & 2000 & $1.42^{[\mathrm{e}]}$ \\
\hline D,L-Lactide & DMF (1M) & $3 \mathrm{~h}$ & & $>99$ & 2100 & 3150 & 1.50 \\
\hline $\begin{array}{c}\mathrm{S}=\mathrm{C}=\mathrm{S} \\
\text { carbon disulfide }\end{array}$ & DMF (1M) & $2 \mathrm{~h}^{[c]}$ & -S-C(S)-S- & $>99$ & 21200 & 35600 & $1.68^{[\mathrm{d}]}$ \\
\hline Styrene & neat & $24 \mathrm{~h}$ & & 0 & - & - & - \\
\hline $\begin{array}{l}\text { C } \\
\text { Vinyl Acetate }\end{array}$ & neat & $24 \mathrm{~h}$ & & 0 & - & - & - \\
\hline
\end{tabular}

[a] Monomer (1 equiv.), OED-2 (5 mol\%), neat or DMF (1M), $25^{\circ} \mathrm{C}, \mathrm{Ar} . \mathrm{M}_{\mathrm{n}}$ and $M_{\mathrm{w}}$ determined by SEC analysis (Eluent THF). [b] ${ }^{1} \mathrm{H}$ NMR conversion. [c] Time not optimized. [d] SEC analysis (Eluent DMF). [e] SEC analysis (Eluent $\mathrm{H}_{2} \mathrm{O} / \mathrm{MeOH}$ ).
Usually prepared upon photolysis or under high pressure, ${ }^{[12]}$ the carbon disulfide polymer, an important class of organic conductor, was smoothly obtained with high molar masses from liquid carbon disulfide $\left(\mathrm{CS}_{2}\right)$.

Thus, the organic reducer OED-2 was able to initiate the polymerization of a lactone and diverse alkenes bearing activating substituents. Unfortunately, less activated alkenes, such as styrene or vinyl acetate, could not be polymerized. The reduction potentials of methyl and ethyl methacrylate were measured at -2.45 and $-2.53 \mathrm{~V}$ vs SCE in DMF, ${ }^{[11]}$ i.e. in the array of redox potentials that the effective reducing power of OED-2 can reportedly attain. ${ }^{[13]}$ In contrast, at potentials up to $3.1 \mathrm{~V}$ vs SCE, no reduction wave was observed for styrene and vinyl acetate by cyclic voltammetry. The inability of OED-2 to reduce these monomers certainly explains the absence of polymerization.

To evaluate the nonterminating character of the propagating anion stabilized by OED-22+, we explored the synthesis of welldefined block copolymers by sequential addition of monomers. After complete MMA consumption to form PMMA, a second monomer (EtMA) was added to the stirred reaction and also polymerized quantitatively (Scheme 2). The blood red color, characteristic of propagating anions, persisted until the solution was exposed to air. ${ }^{1} \mathrm{H}$ NMR and SEC analysis confirmed the formation of a PMMA-b-PEtMA copolymer as represented by increased molecular weights compared to the PMMA homopolymer.

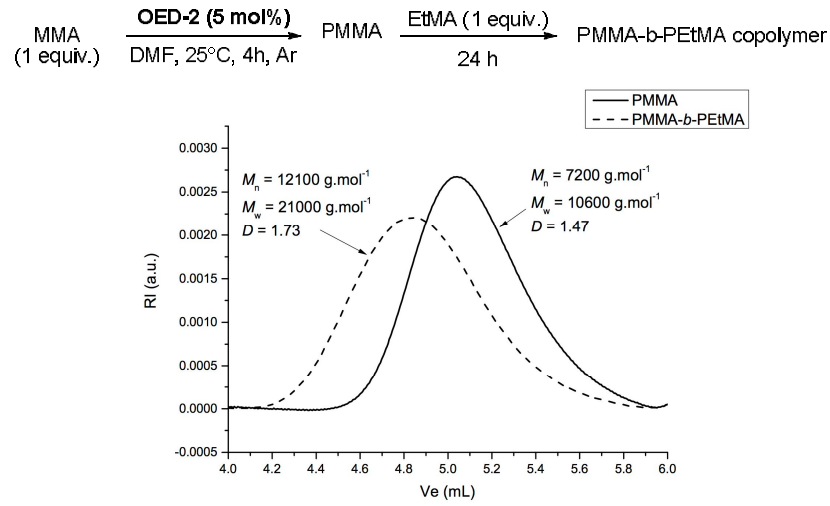

Scheme 2. Synthesis of a PMMA-b-PEtMA copolymer

Several experiments were performed to gain insight into the mechanism of polymerization initiated by OED-2. First, we focused on the initiation mode since organic electron donors can act as nucleophile, as base or as reducing agent. ${ }^{[14]}$ Initiation by attack of the nucleophilic double bond of OED-2 on the monomer would involve the incorporation of the reducer as an end group of the polymer chain. Yet, no characteristic proton of OED-2 was observed on the ${ }^{1} \mathrm{H}$ NMR of the purified polymer PEtMA. ${ }^{[11]}$ Moreover, no polymerization in the presence of other electron-rich tetraminoethylenes, such as TDAE, was observed (Table 1, Entry 1). Although not reported for OED-2, another possible source of nucleophilic initiator comes from the existence in solution of equilibrium between aminoethylenes and 
the corresponding carbenes. ${ }^{[15]} \mathrm{N}$-heterocyclic carbenes $(\mathrm{NHC})$, such as the 1,3-bis(2,4,6-trimethylphenyl)imidazol-2-ylidene (IMes), are well known organocatalysts in polymer synthesis. ${ }^{[16]}$ However, co-initiators are usually required to avoid the formation of non-reactive single-addition product. ${ }^{[17]}$ Under our reaction conditions, IMes-mediated polymerization of EMA gave small oligomers $(200<\mathrm{M}<3400)$ with a low conversion rate of $27 \%$ (Table 3, entry 9). NHC-initiated polymerization reactions are quenched by adding carbon disulfide in order to irreversibly trap the $\mathrm{NHC}$ within a zwitterionic $\mathrm{NHC}-\mathrm{CS}_{2}$ adduct. ${ }^{[18]}$ In our case, the polymerization of $\mathrm{CS}_{2}$ by OED-2 (Table 2) irrefutably excluded the intervention of a carbene intermediate.

Since OED-2 contains non-bonded electron pairs on its nitrogen atoms, it is in principle sensitive to protons. We postulated that if OED-2 behaved like a basic amine in catalyzing the polymerization, similar results should be obtained with the structurally related 4-(dimethylamino)pyridine (DMAP). In the presence of a nucleophilic initiator such as an alcohol, DMAP is able to catalyze polymerization processes like the ringopening polymerization of L-lactide. ${ }^{[19]}$ Under our alcohol-free conditions, DMAP did not catalyze the polymerization of the EMA (Table 3, Entry 8 ) nor the polymerization of the D,L-lactide (not in the table). It was also observed that the polymerization process initiated by OED-2 was inhibited by the addition of ethanol (Entry 7). We could thus reasonably discount the basic properties of OED-2 and affirm that the activation of the monomer did not imply the formation of a hydrogen bond.

The documented performance of OED-2 as a powerful electron donor in organic synthesis, ${ }^{[1,8]}$ suggests that the initiation of the polymerization was induced by electron-transfers As previously stated, the reactivity of the monomers, varying according to their reduction potentials, and the restriction to highly polar aprotic solvents both support this hypothesis. A change of color, as observed during the reaction, is also typical in electron-transfer reactions and corresponds to the formation of the donor-acceptor charge-transfer complex. Moreover, OED$2^{2+}$ derivatives were observed by ${ }^{1} \mathrm{H}$ NMR at the end of the reaction. Oxygen $\left(\mathrm{O}_{2}\right)$, Copper(II) chloride $\left(\mathrm{CuCl}_{2}\right)$, or paradinitrobenzene ( $p$-DNB) are commonly used as inhibitors in the study of electron-transfer mechanism. ${ }^{[20]}$ Under our reaction conditions, the polymerization was totally inhibited by $\mathrm{CuCl}_{2}, p$ DNB or $\mathrm{O}_{2}$ (Entries 1-3). The inhibition took place regardless of when addition occurred, i.e. at the outset or after 5 minutes of stirring (Reaction stopped at $65 \%$ conversion). These results provide good evidence of a chain initiation pathway via electron transfers.

Secondly, the pathway of the chain propagation was examined. The cyclic voltammogram of OED-2 exhibits a single two-electron redox wave ${ }^{[11]}$ and the formation of principally anionic intermediates promoted by OED-2 has been observed on many occasions. ${ }^{[8]}$ To confirm the predominance of the anionic over radical chain propagation, the polymerization of EMA was conducted in protic solvents. Addition of ethanol or degassed water, ${ }^{[21]}$ at the outset or after $3 \mathrm{~min}$ of stirring, inhibited the reaction by quenching the anionic chain propagation via proton transfer termination (Entries 6-7). In contrast, the use of a large excess of 2,2,6,6-tetramethyl-1- piperidinyloxy (TEMPO) as radical trap did not inhibit the polymerization process (Entries 4-5). Finally, unlike certain monomers that can polymerize either by radical or anionic pathways, D,L-lactide is known to polymerize only by anionic chain propagation.

Table 3. Mechanistic considerations for the polymerization of EMA.[a]

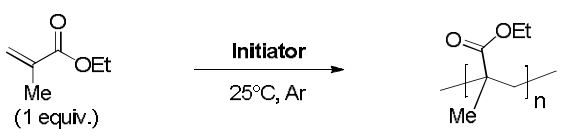

\begin{tabular}{|c|c|c|c|c|c|c|c|}
\hline Entry & $\begin{array}{l}\text { Initiator } \\
(\mathrm{mol} \%)\end{array}$ & Conditions & Time & $\operatorname{Conv}(\%)^{[b]}$ & ] $M_{n}$ & $M_{\mathrm{w}}$ & $\bigoplus$ \\
\hline 1 & OED-2 (5) & $\mathrm{DMF}, \mathrm{O}_{2}$ & $24 \mathrm{~h}$ & 0 & - & - & - \\
\hline 2 & & $\mathrm{DMF}, \mathrm{CuCl}_{2}(10 \mathrm{~mol} \%)$ & $24 \mathrm{~h}$ & 0 & - & - & - \\
\hline 3 & & DMF, $p$-DNB (10 mol\%) & $24 \mathrm{~h}$ & 0 & - & - & - \\
\hline 4 & & DMF, TEMPO (10 mol\%) & $30 \mathrm{~min}$ & 99 & 6200 & 11200 & 1.81 \\
\hline 5 & & DMF, TEMPO (1eq) & $30 \mathrm{~min}$ & 99 & 8300 & 13300 & 1.60 \\
\hline 6 & & $\mathrm{H}_{2} \mathrm{O}_{\text {(Degassed) }}$ & $24 \mathrm{~h}$ & 0 & - & - & - \\
\hline 7 & & $\mathrm{EtOH}$ & $24 \mathrm{~h}$ & 0 & - & - & - \\
\hline 8 & DMAP (10) & neat & $24 \mathrm{~h}$ & 0 & - & - & - \\
\hline 9 & IMes (10) & neat & $24 \mathrm{~h}$ & 27 & \multicolumn{3}{|c|}{$200<M<3400$} \\
\hline
\end{tabular}

[a] EMA (1 equiv.), OED-2 (5 mol\%), solvent $(1 \mathrm{M}), 25^{\circ} \mathrm{C}, \mathrm{Ar} . M_{\mathrm{n}}$ and $M_{\mathrm{w}}$ determined by SEC analysis (Eluent THF). [b] ${ }^{1} \mathrm{H}$ NMR conversion.

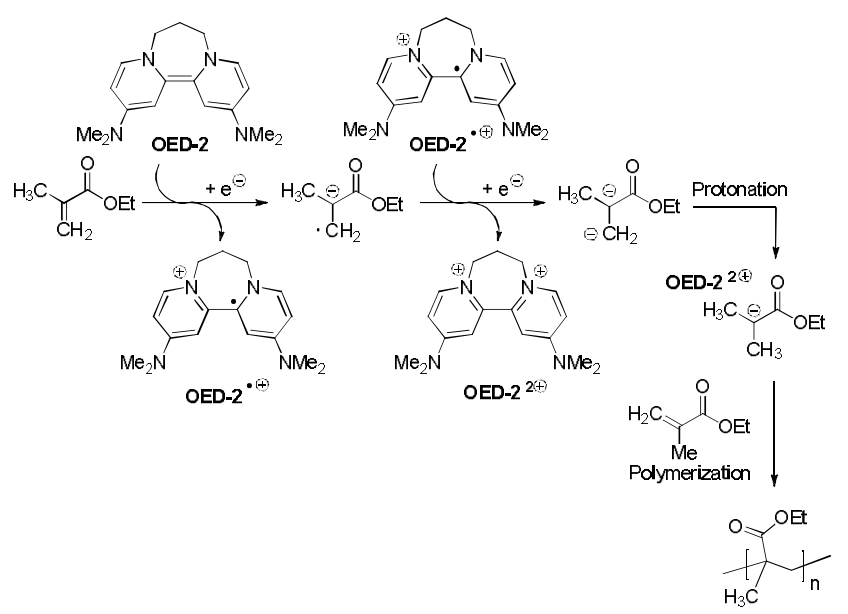

Scheme 3. Proposed polymerization mechanism initiated by OED-2. [22]

As depicted in scheme 3 , these mechanism considerations support the hypothesis of a transfer of electrons from the organic donor OED-2 to the monomer leading to its reduction. The generated anionic intermediate could then initiate the polymerization via anionic chain propagation. Even though several indicators are pointing out the anionic pathway, competing processes cannot be totally excluded and could explain the modest result of our dispersities. We are currently investigating the structures of the initiating and terminating 
fragments incorporated into the polymer chains by mass and NMR spectroscopy.

In conclusion, we report here the first chain-growth polymerization using small amounts of organic reducing agents as initiators. The metal-free polymerization of various activated alkene and cyclic ester monomers was performed in short times and under mild conditions, providing the expected polymers with good polydispersities and without the need for co-initiators or external activation. Organic electron donors are remarkable polymerization initiators, allowing the development of an efficient, simple and room temperature process, responding to energyfriendly, cost-efficient and secure technical specifications. Their high group tolerance makes them fully compatible with the synthesis of a large range of polymers and bio-polymers of wide industrial importance. Our mechanistic considerations support both the initiation through electron transfer and the anionic chain propagation. Moreover, these results open new horizons for OEDs, never previously used in the reduction of alkene or lactone functional groups and intermolecular processes.

\section{Acknowledgements}

This work was supported by the CNRS and Aix-Marseille Université. Dr Maurice Médebielle (ICBMS) is thanks for the cyclic voltammetry studies conducted on monomers. Our thanks to $\mathrm{Dr}$ Omar Khoumeri and $\mathrm{Dr}$ Hervé Clavier for valuable discussions.

Keywords: Chain-growth polymerization • Electron transfer • Organic electron donor $\bullet$ Reduction

[1] For reviews, see: a) J. Broggi, T. Terme, P. Vanelle, Angew. Chem 2014, 126, 392-423; Angew. Chem. Int. Ed. 2014, 53, 384-413; b) J. A Murphy in Encyclopedia of Radicals in Chemistry, Biology and Materials (Eds.: C. Chatgilialoglu, A. Studer), Wiley-VCH, Weinheim, 2012, pp. 817-847; c) S. Zhou, H. Farwaha, J. A. Murphy, Chimia 2012 66, 418-424; d) J. A. Murphy, J. Org. Chem. 2014, 79, 3731-3746; e) E. Doni, J. A. Murphy, Chem. Commun. 2014, 50, 6073-6087.

[2] a) E. Cahard, F. Schoenebeck, J. Garnier, S. P. Y. Cutulic, S. Zhou, J. A. Murphy, Angew. Chem. 2012, 124, 3733-3736; Angew. Chem., Int Ed. 2012, 51, 3673-3676; b) H. S. Farwaha, G. Bucher, J. A. Murphy, Org. Biomol. Chem. 2013, 11, 8073-8081; c) E. Doni, S. O'Sullivan, J. A. Murphy, Angew. Chem. 2013, 125, 2295-2298; Angew. Chem. Int. Ed. 2013, 52, 2239-2242; d) E. Doni, B. Mondal, S. O'Sullivan, T. Tuttle, J. A. Murphy, J. Am. Chem. Soc. 2013, 135, 10934-10937.

[3] Principles of Polymerization, 4th Ed. (Ed.: G. Odian), Wiley \& Sons, Inc., Hoboken, 2004

[4] A. S. Sarac, Prog. Polym. Sci. 1999, 24, 1149-1204.
[5] Z. J. Jedliński, Polym. Sci. Part A. Polym. Chem. 2002, 40, 2158-2165 and references therein.

[6] a) Z. Jedliński, Acc. Chem. Res. 1998, 31, 55-61; b) H. Janeczek, Z. Jedliński, I. Bosek, Macromolecules 1999, 32, 4503-4507; c) H. Janeczek, Z. Jedliński, Polymer 2002, 43, 7219-7223; d) Z. Grobelny, A. Stolarzewicz, A. Maercker, Curr. Org. Chem. 2007, 11, 1126-1134; e) Z. Grobelny, A. Stolarzewicz, B. Piekarnik, A. Maercker, Curr. Org. Chem. 2008, 12, 564-575.

[7] a) T. Ishida, S. Kondo, K. Tsuda, Makromol. Chem. 1977, 178, 32213228; b) K. Tsuda, S. Kondo, K. Yamashita, K. Ito, Makromol. Chem. 1984, 185, 81-89.

[8] a) J. A. Murphy, J. Garnier, S. R. Park, F. Schoenebeck, S.-Z. Zhou, A. T. Turner, Org. Lett. 2008, 10, 1227-1230; b) J. Garnier, A. R. Kennedy, L. E. A. Berlouis, A. T. Turner, J. A. Murphy, Beilstein J. Org. Chem. 2010, 6, 1-8.

[9] a) OED-1 was in-situ generated (See SI): J. A. Murphy, T. A. Khan, S.Z. Zhou, D. W. Thomson, M. Mahesh, Angew. Chem. 2005, 117, 13801384; Angew. Chem. Int. Ed. 2005, 44, 1356-1360; b) J. A. Murphy, S.Z. Zhou, D. W. Thomson, F. Schoenebeck, M. Mahesh, S. R. Park, T. Tuttle, L. E. A. Berlouis, Angew. Chem. 2007, 119, 5270-5275; Angew. Chem. Int. Ed. 2007, 46, 5178-5183.

[10] J. Garnier, D. W. Thomson, S. Zhou, P. I. Jolly, L. E. A. Berlouis, J. A. Murphy, Beilstein J. Org. Chem. 2012, 8, 994-1002.

[11] See SI for details and cyclic voltammetric data.

[12] P. B. Zmolek, H. Sohn, P. K. Gantzel, W. C. Trogler, J. Am. Chem. Soc. 2001, 123, 1199-1207 and references therein.

[13] In solution, the effective redox potentials of organic reducers are much higher than their redox potential determined by electrochemical methods $\left(E_{1 / 2}=-1.24 \mathrm{~V}\right.$ for OED-2)

[14] N. Wiberg, Angew. Chem. 1968, 80, 809-822; Angew. Chem., Int. Ed. 1968, 7, 766-779.

[15] a) T. A. Taton, P. Chen, Angew. Chem. 1996, 108, 1098-1100; Angew. Chem., Int. Ed. Engl. 1996, 35, 1011-1013; b) P. I. Jolly, S. Zhou, D. W. Thomson, J. Garnier, J. A. Parkinson, T. Tuttle, J. A. Murphy, Chem. Sci. 2012, 3, 1675-1679.

[16] a) N. E. Kamber, W. Jeong, R. M. Waymouth, R. C. Pratt, B. G. G Lohmeijer, J. L. Hedrick, Chem. Rev. 2007, 107, 5813-5840; b) M. K Kiesewetter, E. J. Shin, J. L. Hedrick, R. M. Waymouth, Macromolecules 2010, 43, 2093-2107; c) M. Fèvre, J. Pinaud, Y. Gnanou, J. Vignolle, D. Taton, Chem. Soc. Rev. 2013, 42, 2142-2172.

[17] Y. Zhang, E. Y. X. Chen, Angew. Chem. 2012, 124, 2515-2519; Angew. Chem., Int. Ed., 2012, 51, 2465-2469.

[18] G. W. Nyce, S. Csihony, R. M. Waymouth, J. L. Hedrick, Chem. Eur. J. 2004, 10, 4073-4079.

[19] F. Nederberg, E. F. Connor, M. Möller, T. Glauser, J. L. Hedrick, Angew. Chem. 2001, 113, 2784-2787; Angew. Chem., Int. Ed. 2001, 40, 27122715.

[20] R. A. Rossi, A. B. Pierini, A. B. Peñéñory, Chem. Rev. 2003, 103, 71 167.

[21] As already demonstrated, ,2] $^{\text {a] }}$ degassed water does not inhibit electron transfers between OED-2 and substrates.

[22] Inspired by the mechanism proposed in reference [6b] for polymerization initiated by metal-mediated electron-transfers 


\section{Layout 1:}

\section{COMMUNICATION}

The metal-free polymerization of various activated alkene and cyclic ester monomers was rapidly performed under mild conditions, using organic electron donors (OED) as initiators and without the need for co-initiators or external activation methods. Hence, OED-initiators allow the development of an efficient, simple and room temperature process, responding to energy-friendly, costefficient and secure technical specifications

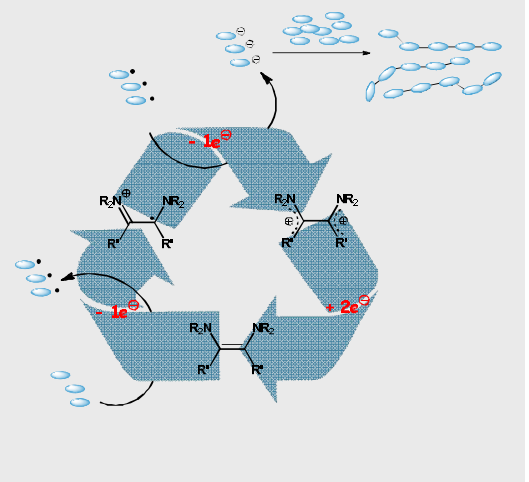

Julie Broggi, * Marion Rollet, Jean-Louis Clément, Gabriel Canard, Thierry

Terme, Didier Gigmes, and Patrice Vanelle*

Page No. - Page No.

Polymerization Initiated by Organic Electron Donors 